morning, and is apparently in good health. At first, the thyroid was pushed until the onset of disagreeable symptoms, using about 3 grains three times a day; then I gave about half the former dosage, and latterly the thyroid has been given once daily.

Di. A. JACCBI, New York-I desire to specially emphasize the probability of a correlation of the ductless glands. We are in the habit of generally attending to one, and not infrequently with an indiflerent result. I believe that many of the failures of poor treatment are dependent on this, because 1 think it would be well, for practical reasons, to combine the extracts of sercral of these glands in insuficient or faulty devclopment. In a number of instances in which I have done this the results have seemed to be better. In myxedema, however, thrroid feeding is usually sufficient. I wish also to direct attention to a point in the gross anatomy. We have been told in the paper that Virchow, fifty years ago, drew our attention to tlie condition of the base of the cranium-the shortening of the cranium observed in most cases of cretinism. This shortness is the result of early synchondrosis between the splenoid and accipital bones. When a rachitis develops after birth and the bones become eburnated the limbs remain short; if rachitis runs its full course before birth there is calcification of the oceipito-sphenoid synchondrosis before that time; hence the base of the cranium remains short, and this explains why the basal ganglia of the brain can not develop. This should not be lost sight of. I think it was Baillarger who first pointed that out, even before Virchow. What has been called fetal rachitis resembles myxedema more than it does rachitis; they are not the same histologically. We have been prone to forget this important fact in recent years. I was particularly interested when this subject was presented in 1853 , and, hence, in $1857 \mathrm{I}$ published a paper on ossification of the sutures and fontanelles of the cranium. Since that time I have seen a good many such cases, and have found that whether they are improved by thyroid or not, if the base of the cranium is short, the improvement will not be marked. I have in the hospital now a child of 6 years looking like a baby of 14 months. The fontanelle is four times the normal size, and all of the teeth are decayed. There is a large thyroid and a still larger thymus. There was no evidence of intellect until thyroid was given in very large doses. 'The child took first 2 grains, three times a day, of Welcome and Burrough's preparation, and the dose was gradually run up to 24 grains, three times a day. Then a little tachycardia and perspiration appeared, and the remedy was stopped for a few days, and resumed in the dose of 12 grains, three times daily. This dose has been taken for a long time; it is not an excessive dose in this case, because it does not give rise to bad symptoms; on the contrary, the patient is improving.

Dr. David Ruesman, Philadelphia-In Philadelphia a large number of cases have been presented at society meetings in the last two or three years. I believe that more brilliant and tangible results are to be obtained from preventive medicine in this class of diseases than in any other. The reader of the paper has designated these condilions as congenital or acquired athyrea. If intended to imply a functional athyrea, the term is well chosen; but otherwise, not: for only in sporadic cases is the thyroid generally absent. But I take it that the author means to refer to a functional athyrea. With regard to achondroplasia, I would say that histologically it has nothing to do with rickets, nor is it identical with cretinism. One of the differential points is that in achondroplasia there is penetration of the periosteum inward, between the epiphysis and the diaphysis - a peculiar periosteal ingrowth, which is not seen in cretinism. There is also a sclerosis of the marrow of the diaphyses of the long bones in the former affection.

In connection with cretinism and achondroplasia, it is well to consider some other affections, such as infantilism, dwarfism, etc. We can not say that these are not all in some way related; and, from the practical standpoint, it seems to me advisable in all of them to give a trial to thyroid gland. It can do no harm if cautiously used, and may do good. If it does good, we are dealing with a cretinoid state, no matter what else may be present. In endemic cretinism, thyroid gland has not accomplished much. This would surprise us if we did not know the attending circumstances. The reasons are these: In the first place, the cause persists in endemic foci, whether in the water or in some other agent. Another cause of failure is that people are ignorant, and will not adopt such remedies as are for their own good. Fortunately endemic cretinism does not exist in this country, though a considerable number of eases have been reported from one part of Canada. Where it does exist, education will accomplish a great deal of good.

Dir. ENGELMaNN-Where the cases are brought under treatment late, there is almost always a hiatus left like that described by Dr. Shelly. In my case there has been a decided advance in growth on using the pituitary gland. When there is general mental and physical retrogression I make use of the thyroid in the morning and pituitary gland in the evening. In my case the only evidence of thyroidism observed was a rise of temperature, and as this caused the child no discomfort, the dose was not reduced. As to Dr. Riesman's criticism, it seems to me a very just one. I have in mind, however, another case in which the gland is very much enlarged and, on second thought, I will allow my name athyrea to stand for it and the former condition as well.

\section{REPORT OF TWO CASES OF DERMOIDS IN CHILDREN :}

ONE OF THE TESTICLE AND ONE OF THE OVARY: WITH NOTES ON THE INFREQUENCY OF THE FIRST: THE ORIGIN OF BOTH.*

SAMUEL W. KELLEY, M.D.

Professor of Diseases of Children, Cleveland College of Physicians and Surgeons; Pediatrist to the Cleveland General Hospital and to the City Hospital, Ftc.

CLEVELAND, OHIO.

In this fragmentary paper I shall first deal with the infrequency of dermoids of the testicle, giving a list of cases hitherto reported; and will give secondly a résumé of the theories of the origin of dermoids; thirdly, the characteristics on which the diagnosis is based, and fourthly and lastly, reports of two cases, one of the testicle and one of the ovary.

CASES OF DERMOIDS OF TESTICLES HITHERTO REPORTED.

In 1885 Verneuil $^{1}$ published an analysis of nine cases, all he was able to find in the literature, to which he added one case observed by himself jointly with $\mathrm{Mr}$. Paul Guersant. Dr. Theodore Kocher ${ }^{2}$ refers to these ten cases of Verneuil and adds four more cases, which were all he was able to find; one each from Tilanus, ${ }^{3}$ Geinitz ${ }^{4}$ in Altenberg, Lang ${ }^{5}$ in Innsbrück and Pitha and Bilroth. ${ }^{6}$ Mr. Holmes (1869) refers to Verneuil's cases and then adds one from Dr. Van Buren of New York. Mr. Curling states (1845) that "Dr. Duncan of Edinburg removed a congenital tumor of the testicle from a boy 8 years of age. Dr. Goodsir examined the tumor and found skin, hairs and portions of cartilage in it," and he mentions Erichsen's allusion to Mr. Marshall's $\operatorname{case}^{8}$ (1852). I do not know whether these cases were among those known to Verneuil.

In 1886, D'Arcy Power' reported a case and exhibited before the London Pathological Society a specimen of a dermoid tumor of the testicle removed from a boy of 4 years. Power remarks that in the previous 200 years only ten cases had been recorded. Possibly he alludes to those collected by Verneuil. Manly ${ }^{10}$ reported a case (in a man 61 years old) before the New York

* Read at the Fifty-third Annual Meeting of the American Medical Association, in the Section on Diseases of Children, and approved for publication by the Executive Committee
Rosenthal. H. M. McClanahan and Samuel W. Kelley. 
Academy of Medicine Feb. 14, 1899. C. C. Morris ${ }^{11}$ reports a case of dermoid of the testicle removed by him from a boy of 12 years.

These are the only cases that a cursory look through the literature brought to my notice. There are probably others, but dermoids of the testicle certainly are not common, for Mr. Curling, with all his vast experience, writes as follows: ${ }^{12}$ Cysts containing skin. hair, bone, teeth and other structures foreign to the part have, in some rare instances, been found in the scrotum in connection with the testicle. No case of the kind has fallen under my notice."

Senn says (1900): "There is no doubt that most of the cases of dermoid tumors of the testicle that have been reported were not within the testicle, but were on it-that is, were dermoids of the scrotum. That dermoids in this locality are not common is evident from the fact that Kocher ${ }^{13}$ found only fourteen cases recorded in literature."

Ovarian dermoids are not nearly so rare as those of the testicle, but the reported cases are more numerous than we can reveiw to-day. However, ovariotomies at the seventh or eighth year have not been so frequent as to be without interest, and my case presented additional symptoms of obstruction of the bowels.

\section{THEORIES OF TIIE ORIGIN OF DERMOIDS.}

It is interesting to read in Guersant's "Surgical Diseases of Children:" which was published in English no longer ago than 1871, the following statement: "In the newborn we sometimes, but quite rarely, meet with cysts in various parts of the body which contain the bones, teeth, hair and different portions of a fetus. These curious and familiar facts may be explained by the unequal development of two germs, one of which is encroached upon by the other, and remains, so to speak, nestled in it. They are sometimes for a very long time stationary, and in some cases terminate in inflammation." Thus dermoid cysts and fetal inclusions were confused. Again, in his chapter on cancer of the testicle, Guersant warns against confounding "these degenerated testicles with tumors produced by a false conception, sometimes seen in this region."

Holmes" writes (1869): "Dermoid tumors, when they occur in later life, are justly regarded as having no relation to fetal inclusion; but if one should be of congenital origin it might be difficult to distinguish it from an included fetal formation. Again, Mr. Holmes ${ }^{15}$ writes: "The tumors of the testicle and scrotum met in children are almost all of a cancerous nature, or cystic, or included fetal remains. . . . Congenital dermoid cyst, or so-called fetal inclusion, is an affection very rarely met. . . . Teeth, bone and hair are the most common structures found in these cysts. As in those of the sacral region, . . . their real nature is doubtful. Some pathologists regard them as portions of a second fetus originally developed in the abdomen and following the testicle in its descent; others believe also in their fetal origin, but consider that they are originally developed in or near the testis; while the more general opinion at the present time seems to be that they bear more analogy to the dermoid cysts, such as are found so commonly in the orbit, than to cases of fetal inclusion. I incline to the latter view, founding my opinion partly on the analogy of such cases as that of Sir B. Brodie and Mr. Athol Johnson's, above referred to. In such cases tumors which arise congenitally are found, after death or removal, to contain scattered through their substance irregular masses of bone and other structures, but to present no evidence of any inclusion. The difficulty in the way of accepting this view of the congenital scrotal tumors is the occasional occurrence in them of structures (such as the gray matter of the brain in one case) which is ordinarily regarded as of too high organization to be produced by morbid action. Allowing, however, the accuracy of the observations, and admitting the fetal origin of such tumors as those which present compound tissue of this kind, we may still say that for the majority of congenital tumors in this region no different origin from that of the ordinary dermoid cysts has as yet been proved."

As you are well aware, the generally accepted opinion at the present day is that. dermoids are caused, not by inclusion of one individual by another, but by disassociation or dislocation of some of the blastodermic elements of one individual; in other words, by an accidental malposition of a portion of one or more of the layers of the blastoderm, which took place during the developmental infolding of these various layers. These misplaced matrices developing produce specimens of their various structures-for instance, skin or mucous membrane, or epithelial cells (columnar, ciliated or squamous), hair follicles and consequently hair, sweat glands and their resultant secretions, teeth, bone, cartilage or nerve tissue; simple or more complex according to the nature of the embryonal elements that are displaced and intermingled. This places them in a class by themselvesthe teratomata, distinguished from all other classes of tumors in which only one blastodermic layer is represented.

This theory of their origin also is supposed to account for the position in which dermoids are most often found, namely, where the different germinal layers fold in and coalesce, near the orbit, in the neck, in the coccygeal region, in the ovary, in the testicle or scrotum. Though they have been found in various other regions.

But now it seems that some embryologists claim that after impregnation of an ovum a single segmentation cell may split off before the establishment of the germ layers. And they say that it may be presumed as probable that almost up to the formation of the germinal layers any single segmentation cell even if dislocated, possesses the potentiality of producing all of the layers if necessary. So that if a cell of this kind were caught and infolded in the layers formed by the other cells it might proceed to develop into a parasitic growth of complex or organized structure.

In that case the difference in the origin of included fetus and of dermoid tumor would be that the former came from dissociated segmentation cell, while the latter was derived from a misplacement taking place after the formation of the layers.

In 1895 Max Wilms ${ }^{18}$ published the results of careful and extensive studies, in which he claims that dermoids of the ovary are not teratomata, and are therefore not present congenitally; but that they are formed directly from an ovule in the ovary, by a kind of parthenogenesis. Kroemer's studies support the views of Wilms; and Kroemer shows that it is hardly proper to call the process parthenogenesis because, while this is a normal process in lower plant and animal life for the propagation of species, in the case in hand it is a pathologic process in which the growth and development of organs or portions of organs are atypical and without any definite law. Dr. Hans Arnsperger ${ }^{17}$ agrees with Wilms and Kroemer, and they all take the view that the embryologic parts are formed from the ovule and the cystic parts from the follicle. Wilms explains dermoid 
cysts of the testicle in somewhat the same manner, by a pathologic growth of the sperm cell. Wilms proposed the name "rudimentary parasites" or "embryomata" for encysted tumors and "embryoid tumors" for the solid variety.

B. Novy ${ }^{18}$ announces after a series of microscopic studies, results virtually agreeing with the views of Wilms, who seems to be the first to have advanced proof of the ovulogenous theory. Dr. Francis Munch ${ }^{19}$ gives an elaborate critical review of Wilms' work. After referring to the fact that dermoid cysts of the ovaries and testicles are distinguished from dermoid cysts occurring elsewhere, in that they are composed of three layers of the blastoderm, namely, the ectoderm, the endoderm and the mesoderm, Munch suggests the name of tridermic tumors as more appropriate than the name proposed by Wilms. He seems convinced that the theory of the parthenogenetic origin of these tumors so far as the ovary is concerned is well sustained, but that the exact similarity of those occurring in the testicles has not yet been definitely proven, although they are probably also of parthenogenetic origin.

This subject is very curious and fascinating, but let us take up something more practical and understandable.

\section{THE CHARACTERISTICS OF DERMOIDS.}

The characteristics on which the diagnosis clinically of dermoids is based are: the position, where the embryonal layers blend or of the testicle or ovary; the time of their appearance, which may be congenital or later. of course, the beginnings of all dermoids, as of all teratomata, are present at birth and may be noticed then or they may not be discovered until later. According to Wilms these "rudimentary parasites" or "embryomata" of the testicle or ovary form an exception, or rather are put in a class separate from the teratomata. They are slow of growth and are painless unless inflamed. They may or may not fluctuate, according to whether they are cystic or solid, flaccid or tensely filled; or the same tumor may fluctuate in one part and be perfectly unyielding in another. Subcutaneous dermoids are not connected with the skin. They do not implicate adjacent glands unless inflamed or the seat of carcinomata.

It is to be remembered that sarcoma is the most common of the abdominal tumors found in childhood. That ovarian tumors in childhood are very rare; and when present are most apt to be dermoid cysts, carcinomata or teratomata. Also, that a dermoid may become the seat of carcinoma.

REPORTS OF TWO CASES. ONE OF THE TESTICLE AND ONE OF THE OVARY.

CASE 1.-The first case I have to report is the following: Wm. T., aged $2 \frac{1}{2}$ years, was brought to me by his mother on account of a growth of the size of an English walnut in the situation of the left testicle. She was positive it had not been there at birth nor until he was a year old; but since appearing it had grown slowly, but steadily, notwithstanding they had used both internal medicines and local applications from several physicians. I found the tumor firm, the lower end being of a bony hardness and the upper portion, though fluctuating slightly, very tense. No pain, redness, tenderness, nor apparent heat. The scrotum was movable over it. The veins showed rather large and blue over its surface. There was no enlargement of adjacent lymphatics. Upon these data I based a diagnosis of a dermoid cyst, and advised its removal.

The parents consenting, I removed it in the presence of Drs. E. S. McIntosh and Alice M. Perry. The tumor corresponded anatomically to the testicle and did not involve any structure but the testicle. It was easily dissected out.
Only the spermatic artery required tying. I closed the wound with catgut, and dressed with iodoform gauze. He made a good recovery, and is now a large, healthy boy, seven and onehalf years after.

The tumor contained bone, fine hairs and several cavities filled with the sebaceous appearing material found in dermoids.

CASE 2.-The other case I have to report is that of Elsie M., a girl of 7 years and 10 months. She is American born of German parents, who had six children, one of whom, the firstborn,

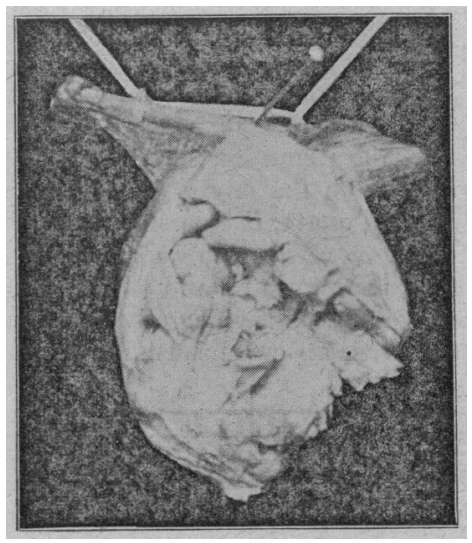

Fig. 1.-Dermoid of testicle. About one-half natural size.

was always sickly and died of "teething" at 16 months. Two children older and two younger than Elsie are now living and healthy. Elsie was small for her age, weighing $41 \frac{112}{2}$ pounds. (The average weight for girls at seven years is 48 pounds, at eight 52.9 pounds.) She appeared a rather pale and delicate, fair and flaxen-haired little girl, but bright and lively. When I was called to see her on June 11, 1900, they told me she had

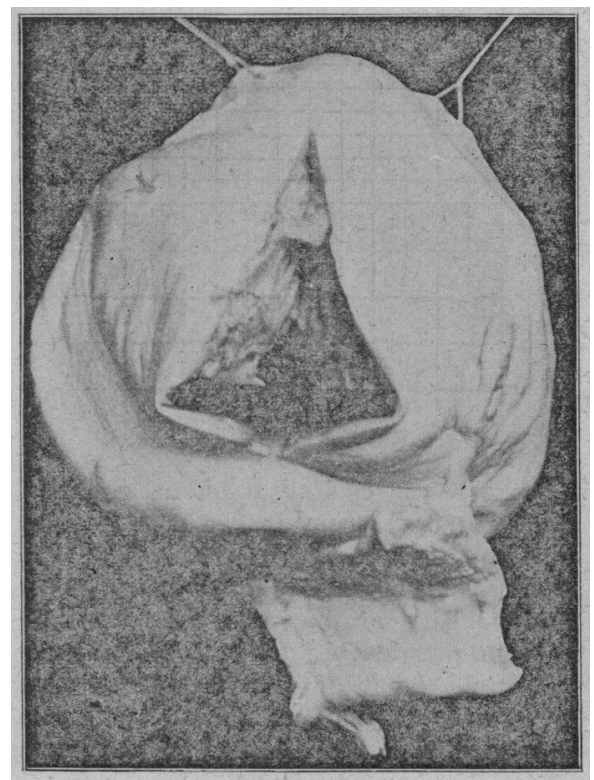

Fig. 2.-Dermoid of ovary. About one-half natural size.

had no children's diseases but whooping cough when a babe and measles at 5 years of age. But that $2 \frac{1}{2}$ mont ${ }_{14}$ previously she had been very sick with what had been called "inflammation of the bowels," with severe pain in the abdomen, some obstruction of the bowels, etc. During this sickness a "lump" was discovered in the region of the bladder. This was the first suspicion that the parents had of a tumor. She urinated frequently and urgently.

Seven weeks later she had suffered a second similar attack, which was severe for $4 \frac{1}{2}$ days, when it subsided rather promptly. 
On my first examination, June 11,1900 , the tumor was easily palpable in the hypogastric region and scemed to be of the shape of a distended bladder. It exterded nearly to the umbilicus, was dull on percussion, and firm, no fluctuation being made out. It was only slightly movable in its position. On catheterization I drew off $1 / 2$ ounce of urine, of a strongly acid reaction. Evacuation of the urine made no difference in the tumor. On digital examination per rectum I found the uterus normal, but I could not satisfy myself about the ovaries. The tumor seemed to be at the fundus of the bladder.

June 18 I examined her again. The tumor was much more movable. I could press it upward till its upper margin was nearly an inch above the umbilicus and a space separated it from the os pubis, and could move it to either right or left of the middle line. On the previous day the child had had an attack of pain lasting about an hour. She had passed only about a pint of urine on the day of the pain, though she generally passed nearly a quart, it was said.

June 25 the tumor was much more freely movable than before. I could move it upward and to the left lumbar region freely-not so far to the right side. By this time I was pretty sure I had to deal with an ovarian tumor on the left side, and an exaggerated Trendelenburg position, massaged and manipulated the abdomen carefully and used a copious enema. These maneuvers were rewarded with a prompt relief of the pain and a free escape of feces and intestinal gases. That ended the attack of "inflammation of the bowels" and I believe my theory as to the cause of the obstruction was correct.

By this time the parents were convinced that the tumor must be removed. However, it was not until September that they would give final consent. On September 29 I operated on her at the Cleveland General Hospital, removing the tumor through a small median incision without any particular difficulty. It proved to be a dermoid cyst of the left ovary, of the size of an orange and consisting of a cyst containing fluid and a solid portion containing irregular-shaped pieces of cartilage, part of which is ossified, masses of atheromatous material and fine hairs.

The accompanying chart shows the progress of the case after operation. The slight rise of temperature in the second week was due to digestive disturbance merely, and was soon relieved. She made a fine recovery, went home two weeks after the operation, and has been well and has gone to school ever since.

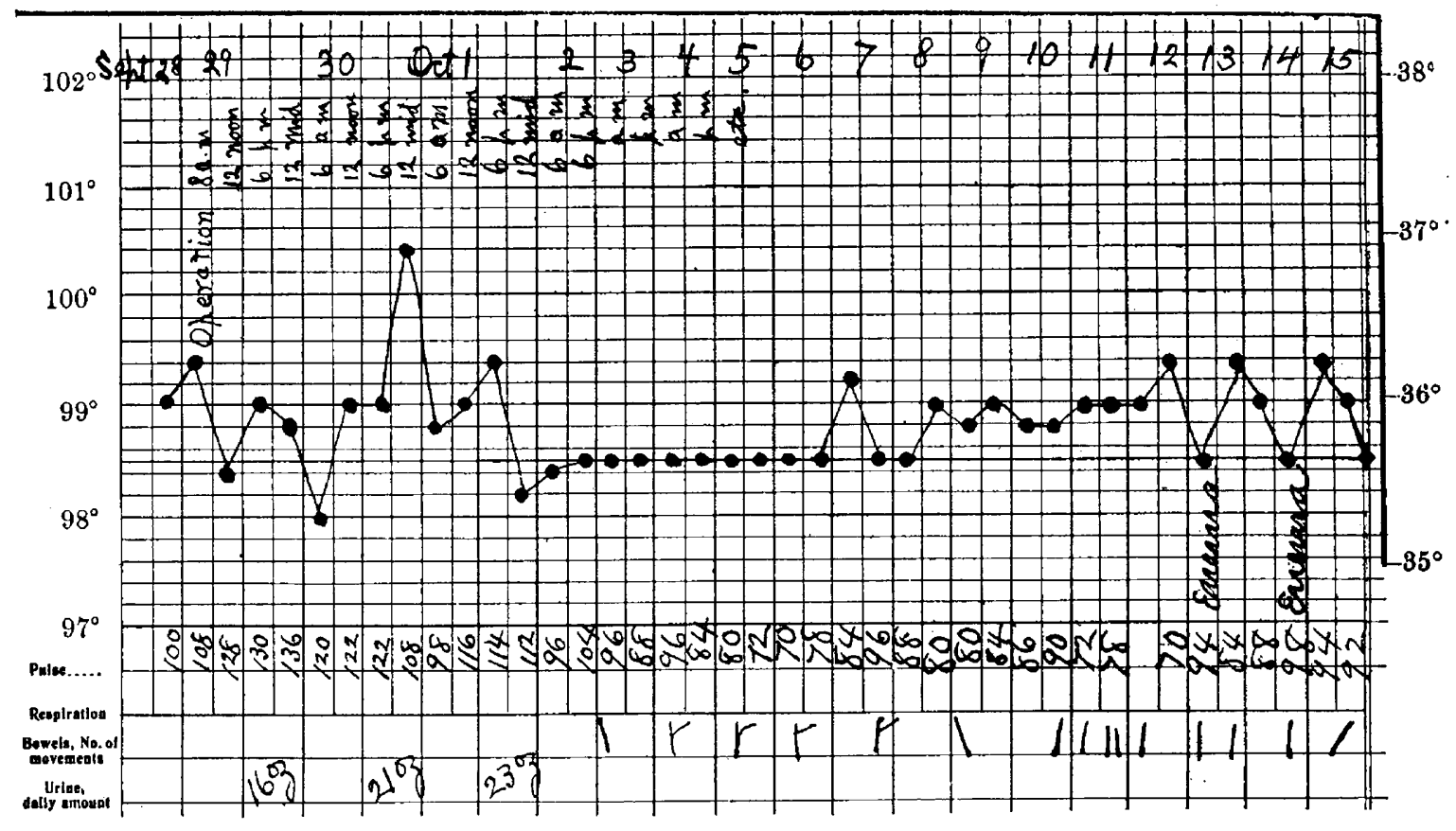

Figure 3.

probably i dermoid, and on July $9 \Upsilon$ tried to get a skiagraph or a view with the fluoroscope in the hope of seeing teeth or bones, but without any satisfactory result.

I advised operation, but the parents refused, although I explained the possibility of danger from the superrention of malignancy, from purulent infiammation and resultant peritonitis which might be fatal or cause aủhesions and render removal of the tumor more difficult later, from twisted pedicle, from obstruction of the bowels, or from pressure on the bladder. I gave her albuminate of iron, for she was rather anemic, and a mixture of acet. et citrate of potassium for the acid urine.

On July 23 I was summoned in alarm to see Elsie in what appeared to be the onset of another attack of "inflammation of the bowels," her parents said. I found her with extreme abdominal pain, worse in paroxysms, a quick pulse and partial obstruction of the bowels. They had given enemata and applied heat without any relief.

Aside from the ordinary causes of pain this might be caused by a twisted pedicle; but with the symptoms of obstruction I reasoned that probably a loop of intestine had slipped from behind the tumor and was imprisoned behind the tumor and between the tumor or its pedicle and the spine. So 1 placed the patient's body almust vertically with the head downward in
BIBLIOGRAPHY.

1. Archives Generales de Medicine 5e serie t. $\nabla$ et $\nabla 1$.

2. Kranklheiten des Hodens und seiner Hüllien, des Nebenhodens Samenstrangs und der Samenblasen, p. 390.

3. Schmidt's Yahrbücher, $100,171$.

4. Deutsche Klinik, $180^{\circ}$.

5. Virchow's Archiv, Ld. 53

6. Chirurgie, Bd. iii, Abth. ii, T. Lief'g.

7 . Referred to in the New Syd. Soc. Bien. Retrospect for 1865-6, p. 33 .

8. On Diseases of the Testis, p. 406.

9. London Lancet, Oct. 23, 1886.

10. Jour. Cutan. and Genito-Urinary Diseases, $\vee, 17$ (1889), p. 220 .

11. St. Louis Med. Review, vol. xliv, No. 19, p. 326, Nov. 9, 1901

12. On Diseases of the T'estis, by T. B. Curling, p. 406.

13. T'athology and Surgical Treatment of Tumors, 1900 , p. 655 .

14. Holmes' Surgical Diseases of Children, p. 7 .

15. Holmes' Surgical Diseases of Children, p. 62J.

16. Leutsche Archiv f. Klin. Med., Bd. 1v.

17. Archiv für Patholog. Anat. und Physiologie und für Klin. Med., Bd. 156. (Fünfzehnte Folge, Bd. vi.) Hft. i. Zur Lehre von dem sogenannten Dermoidcysten des Ovarium.

18. Wiener Klinische Rundschau, Aug. 6, 1809.

19. Semaine Medicale, Sept. 6-13, 1899.

"The discovery of what is true and the practice of that which is good are the two most important objects of philosophy."-Junius. 